BMJ Surgery, Interventions, \& Health Technologies

\title{
Evolution of transanal total mesorectal excision according to the IDEAL framework
}

\author{
Sapho Xenia Roodbeen, ${ }^{\oplus 1}$ Annalisa lo Conte, ${ }^{2}$ Allison Hirst, ${ }^{3}$ Marta Penna, ${ }^{4}$ \\ Willem A Bemelman, ${ }^{1}$ Pieter J Tanis, ${ }^{1}$ Roel Hompes ${ }^{1}$
}

To cite: Roodbeen SX, lo Conte A, Hirst A, et al. Evolution of transanal total mesorectal excision according to the IDEAL framework. BMJ Surg Interv Health Technologies 2019;1:e000004. doi:10.1136/ bmjsit-2019-000004

Received 20 March 2019 Revised 21 May 2019 Accepted 06 June 2019

\section{Check for updates}

(C) Author(s) (or their employer(s)) 2019. Re-use permitted under CC BY-NC. No commercial re-use. See rights and permissions. Published by BMJ.

\section{${ }^{1}$ Surgery, Amsterdam} UMC,University of Amsterdam, Amsterdam, The Netherlands ${ }^{2}$ Surgery, Mater Dei Hospital, Rome, Italy

${ }^{3}$ Nuffield Department of Surgical Sciences, University of Oxford, Oxford, UK

${ }^{4}$ Surgery, Churchill University Hospitals, NHS Foundation Trust, Oxford, UK

Correspondence to Sapho Xenia Roodbeen; s.x.roodbeen@amc.uva.nl

\section{ABSTRACT}

Tremendous innovations have taken place in surgical procedures, but contrary to drug development, this process has been unregulated in the past. IDEAL promotes a structured framework for the safe implementation and assessment of a new surgical technique or intervention, by describing five stages for evaluating and reporting of innovations: Idea, Development, Exploration, Assessment and Long term. Transanal total mesorectal excision (TaTME) is a relatively new technique in rectal cancer surgery that has attracted huge interest and increasing adoption worldwide. This review article aims to provide an overview of the evolution of TaTME, according to the IDEAL framework, which guides us in the difficult yet exciting process of surgical innovation.

\section{INTRODUCTION}

The medical world is evolving and innovating faster than ever. In order to prevent harm, this process of innovation requires regulation, derived from evidence-based principles, rather than uncontrolled experimenting. For drugs and therapeutic biological products, the introduction of new agents is strictly regulated and new drugs can only be widely distributed after going through a four-phase regulatory drug approval process and meeting mandatory requirements. ${ }^{1}$ The process of surgical innovation, however, is complex and has been unregulated and unstructured in the past. This possibly exposes patients to an unethical higher risk and harm. Multiple factors challenge the feasibility of formal assessment of surgical innovations: the intrinsic complexity of surgical techniques, varying expertise of individual surgeons and the constant ongoing innovation of surgery. Although evidence-based healthcare has been endorsed by the surgical community, there is still a considerable lack of well-designed and properly powered randomized controlled trials (RCT). ${ }^{2}$

In rectal cancer surgery, a tremendous evolution has taken place from open to minimal invasive techniques, and other techniques are

\section{Key messages}

What is already known on the subject?

- The IDEAL framework is a guidance in how to get from an idea to safe implementation, by thorough assessment of all the stages of development of a new surgical innovation. This article was written in order to assess how the evolution of transanal total mesorectal excision (TaTME) followed the steps of the IDEAL framework.

\section{What are the new findings?}

- This review article clarifies the lessons learned during adoption and implementation of TaTME. The development of TaTME followed the IDEAL framework quite closely. However, a too rapid uptake of the technique by the early majority resulted in a shift to the Assessment phase when the technique was not completely standardized yet.

\section{How might these results affect future} research or surgical practice?

- When introducing a new surgical technique in the future it is important to follow the steps of the IDEAL framework. The standardization and obligation of a formal training program for surgeons is paramount before widespread adoption of a new technique can take place.

being pioneered continuously, with the aim to improve patient outcomes. Nevertheless, the majority of these newer techniques are a pure abdominal approach which remains technically challenging, particularly for low rectal cancers in a narrow deep pelvis. Transanal total mesorectal excision (TaTME) is the latest surgical technique that has the potential to overcome these drawbacks and has attracted a huge interest worldwide. TaTME is essentially an amalgamation of well-established surgical techniques and principles: TME surgery, as proposed by Heald, ${ }^{3}$ transabdominal transanal approach (TATA), transanal endoscopic microsurgery (TEM) and transanal minimally invasive surgery (TAMIS). ${ }^{4-6}$ 


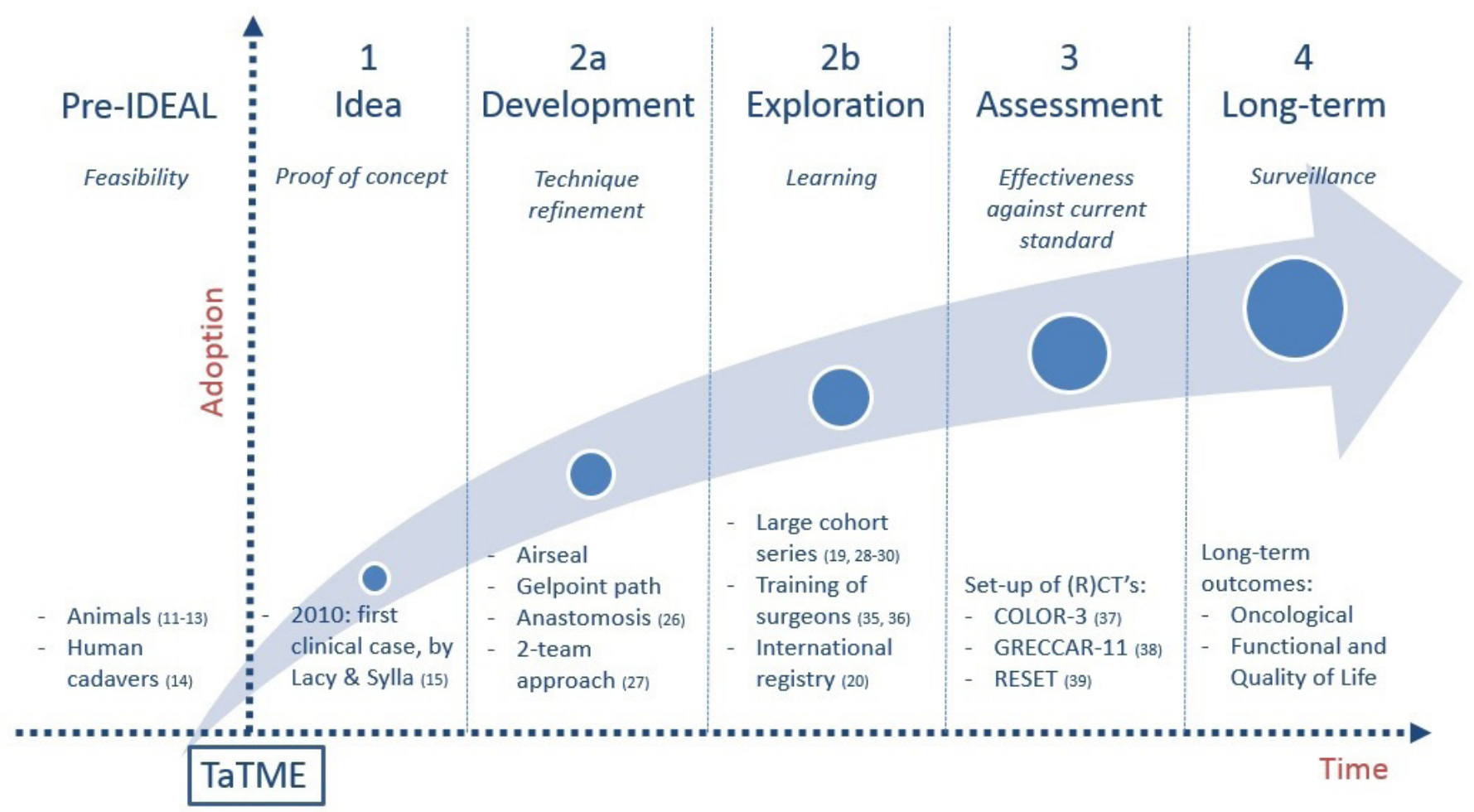

Figure 1 Evolution of transanal total mesorectal excision (TaTME) following the IDEAL framework.

While innovation is exciting, the question remains if these new approaches truly lead to better oncological outcomes and quality of life for patients. Minimal invasive approaches add complexity to the procedure and require an increased skill set. Moreover, patients might be exposed to uncertainties and harm from new complications, inherent in innovative procedures. This highlights the need for a robust framework to introduce new surgical techniques in a safe way and avoid widespread adoption before high-quality assessment has taken place, in order to avoid harm to the patient and to protect the surgeon.

The IDEAL framework (Idea, Development, Exploration, Assessment, and Long-term study) was proposed by the IDEAL collaboration. ${ }^{278}$ Their aim was to establish a rational approach and develop an integrated evaluation pathway for surgical and other complex interventions. The framework is a guidance in how to get from an idea to safe implementation, by thorough assessment of all the stages of development of a new surgical innovation. IDEAL promotes a shift away from the traditional, uncontrolled, retrospective case series that compose most of surgical research, towards planned prospective observational studies leading to high-quality RCTs.

Our aim was to describe how TaTME has developed since its introduction, and how this evolution aligned with the steps and recommendations of the IDEAL framework. This is summarised in figure 1 .

\section{Pre-IDEAL}

The pre-IDEAL stage of the framework was recently proposed and added to the initial five-step framework. ${ }^{9}$
In this phase, the feasibility of a new procedure is tested and further developed on cadavers and animals, before starting clinical application.

The first surgeon to present a series of three human cadavers was Mark Whiteford in $2007,{ }^{10}$ who performed sigmoid resections using natural orifice transluminal endoscopic surgery (NOTES) instrumentation. He showed that 'en bloc' lymphadenectomy, primary anastomosis and retrieval of an intact specimen could successfully be performed via a transanal approach, without any incisions. The procedural steps he described actually come very close to what we would now recommend as the essential steps for a radical transanal proctectomy.

Accordingly, different aspects of the procedure were further explored and tested in animal models (pigs) and cadavers, trying to establish whether a full NOTES procedure for rectal resection would be possible. ${ }^{11-13}$

The largest human cadaveric series $(n=32)$ of transanal sigmoid resection via NOTES was conducted between 2008 and 2011, reporting on an intact mesorectum in all the specimens and a trend towards reduction of operative times. $^{14}$

\section{Stage 1: Idea}

Following this extensive preclinical work in the pre-IDEAL stage, focus shifts to the first step of the IDEAL framework. In this phase, the 'proof of concept' takes place; it describes the first clinical case of a new procedure, prompted by the need for a new solution for a clinical problem. Only a small group of surgeons, defined as 'innovators', start performing the procedure on a few highly selected patients. Small case series are written to 
report on any favorable outcomes in order to inform other colleagues, yet it may be even more important to also report on recurrent mistakes and errors to avoid their repetition in the future.

For TaTME, the Idea was to apply the advances in transanal surgery (NOTES, TEM, TATA, TAMIS), to further optimize the TME principle, by performing a transanal minimally invasive TME.

In 2010, Sylla and Lacy reported on the first clinical TaTME case. ${ }^{15} \mathrm{~A}$ healthy 76-year-old woman, without previous abdominal surgery, diagnosed with a T2N1 rectal carcinoma at $8 \mathrm{~cm}$ from the anal verge, was selected to undergo the first TaTME procedure. They performed the procedure through a rigid TEM platform with laparoscopic assistance from above for the initial exploration and sigmoid mobilization. The postoperative course was uneventful and a complete TME specimen was obtained with negative margins. After the success of this initial case, three cases were reported by Lacy et al, ${ }^{16}$ with negative resection margins, good quality of the specimen and without postoperative complications.

As these early reports suggested safety and even potential benefits, some 'early adopters' took up the innovation, and so, around the end of 2012, TaTME moved into the Development phase.

\section{Stage 2A: Development}

In this phase, the focus is on technical development and feasibility of the procedure, in an initial small and selected group of patients. The few innovators have developed personal experience, and some early adopters start to join the innovators. Technical modifications of the technique, including the different steps of the procedure as well as changes to the equipment, are common during this phase. A regulatory ethical process is required at this stage to prospectively register all consecutive patients and report on their outcomes. ${ }^{8}$

A prospective series was presented by the 'early adopters' of 20 well-selected patients with rectal cancer, undergoing a transanal NOTES with laparoscopic abdominal assistance between August 2011 and July 2012 at the Hospital Clinic of Barcelona. ${ }^{17}$ It demonstrated a safe and oncological adequate procedure. Other small series showed the same, encouraging outcomes of TaTME in terms of safety and efficacy. ${ }^{18} 19$

Collaboration is fundamental for further procedural development, and the few innovators and early adopters of TaTME were aware of this. In March 2013, the first international transabdominal TaTME meeting was held in Houston, involving nine surgeons from the USA and Europe. They shared experiences and pitfalls and discussed how these could be tackled, in a way to find a unique standardization of the technique. Key points of discussion were the difference in appearance of the pelvic anatomy from below, technical challenges related to the purse string and anastomosis, and the need to use a multiport rectal device (GelPOINT path transanal; Applied Medical) rather than the rigid platform, for a safe and atraumatic dissection. Furthermore, collaborators decided to prospectively collect data on their patients for analysis and publication within an international registry. ${ }^{20}$

A year later, a second International TaTME Summit was held in Paris, after which current status and modifications of the technique were reported in an official consensus statement. ${ }^{21}$ It outlined three facets of the TaTME procedure: the technique and its indications, training and adoption, data collection and the TaTME registry. Regarding indications, patient selection is difficult in surgery, considering the technique varies among individual surgeons, and patients themselves are varied. The consensus stated TaTME could be used for both benign and malignant procedures where dissection of the distal or mid-rectum is required. TaTME is preferred in males, with low rectal cancers and visceral obesity.

No recommendations were done regarding ethical considerations, although this is crucial at this stage. When developing a new technique, patients are unavoidably exposed to new risks and harm. Well-intentioned surgical experimentation on patients must therefore be regulated and monitored. Bernstein and Bampoe proposed a guideline for determining the need for regulation of novel neurosurgical procedures, and highlighted the need of institutional review boards in this process. ${ }^{22}$

The colorectal team in Oxford was among the early adopters of this new approach and collaborated with the pioneers to further improve the technique, as there were some concerns. They felt that the new TaTME technique was challenging due to the unfamiliar view from below, and demanded a stable field of dissection to properly view the anatomical landmarks. A new platform (AirSeal; ConMed) for more stable pneumorectum and better smoke evacuation was proposed, resulting in increased visibility with more convenient and precise dissection. ${ }^{23}$

Another concern was how to define the correct plane, and, once found, to maintain that plane, since again, landmarks are different with the down to up approach. The fear of getting close to the tumor and/or disrupting the mesorectum leads to reverse coning with the risk of going too wide and ending up in the pelvic sidewall, causing bleeding and damaging anatomical structures (nerves, prostate, vagina and urethra are particularly at risk). Bernardi et al demonstrated specific features during dissection to guide surgeons. The 'triangles' created using appropriate traction can aid in performing a precise dissection in the correct plane, while features described as 'O's can alert surgeons that they are entering a new fascial plane and can avoid incursion into an incorrect plane. ${ }^{24}$ Especially the risk for urethral injury, which is negligible in conventional abdominal TME, requested new methods for localization of the urethra, as assessed by Atallah $e t a l .{ }^{25}$

The formation of a colorectal or coloanal anastomosis is one of the critical steps in TaTME. Compared with standard laparoscopic stapling of the distal rectum, TaTME allows stapling techniques with excellent visualization and avoidance of cross stapling, potentially reducing 
anastomotic leakages, ${ }^{26}$ especially valuable in patients with a narrow pelvis. Penna et al proposed four techniques: a hand-sewn technique for tumors reaching the anorectal junction, a stapler device for higher tumors, with the choice for stapler configuration and diameter depending on tumor and patient characteristics and surgeons' preference. ${ }^{27}$

As one of the innovators, the group of Lacy at the Hospital Clinic of Barcelona presented the promising outcomes of the standardized and refined technique after performing more than 300 TaTMEs, including the description of two synchronous surgeon working teams, to reduce operative time. ${ }^{28}$

At this point, the technique was further developed, based on the experiences of the innovators and early adopters and their collaboration. The technical steps of the procedure were roughly defined when a very rapid uptake occurred of many surgeons and centers implementing TaTME. Hence, not all important steps were transferred from the early adopters to the early majority of surgeons, and the transition to the exploration phase occurred at an early stage.

\section{Stage 2B: Exploration}

In the exploration phase, attention shifts from developing the technical aspects of the procedure to focusing on correct indications, understanding the potential harms and benefits and planning how an RCT can be initiated. The surgical intervention is more widely used, now performed by the innovators, early adopters and early majority of surgeons. Observational studies should prospectively collect data from multiple centers and surgeons, to ensure measurement and comparison of data. Usually large numbers of patients are needed before an RCT is feasible. ${ }^{8}$

Several groups published the first large cohort series of TaTME. ${ }^{192-31}$ The largest cohort study was published by Lacy et al, describing the results of 140 patients, reporting a complete resected TME specimen in $97.1 \%$ of the cases and low morbidity.

In July 2014, the International TaTME Registry ${ }^{20}$ was set up, launched by the UK Pelican Cancer Foundation. Ethical approval for the registry was granted by the UK Health Research Authority (REC reference 15/LO/0499, IRAS project ID 156930). It was designed to quickly collect high-quality data of cases performed all over the world, in order to further identify the potential harms and benefits. The registry has a strong international collaboration and reflects a wide community of practicing surgeons with varying levels of experience.

In 2017, Penna et al reported the first 720 cases that were recorded on the registry. ${ }^{32}$ This was the largest, prospective data series published on TaTME, and an important contribution to the safety assessment of TaTME. Good pathologic outcomes were found: an incomplete specimen in $4.1 \%$ and $\mathrm{R} 1$ resection (tumor or lymph node $\leq 1 \mathrm{~mm}$ from the resection margin) in 2.7\% (16 cases). However, they also reported on some technical difficulties during the procedure, such as an unstable pneumopelvis and smoke-related problems with visualization, leading to visceral injuries, especially five urethral injuries.

Urethral injuries are rarely seen in conventional TME approaches and this type of injury is a specific concern for TaTME. An assessment of the outcomes after cadaveric training in North America ${ }^{33}$ showed a high (trainee-reported) risk of urethral injury after attending a cadaver training course. This suggests that only cadaver workshops are not sufficient to implement this technique safely and highlight the need for a structured training program.

The second international registry paper included 1594 patients and assessed anastomotic failure. ${ }^{34}$ An overall anastomotic failure rate of $15.7 \%$ was found, which included early $(7.8 \%)$ and delayed leaks $(2.0 \%)$. The rate of irradical (R1) resections was $3.9 \%$ and urethral injuries were rare $(0.8 \%)$.

Another rare but clinically important risk associated with TaTME is the occurrence of a carbon dioxide embolus. The first combined paper from the International TaTME Registry and US TaTME registry, currently in press, reports on an incidence of 25/6375 (0.4\%). They recommend awareness among surgeons and anesthetists, as early recognition and management can limit the clinical impact of such a complication..$^{35}$

The advantage of an international registry is to assess the therapeutic effectiveness and safety of TaTME, reflecting 'real world' practice, with surgeons at different stages in their learning curve. This offers a quick and early assessment of a new surgical procedure.

Another important issue of this phase is training, mentoring and learning curve evaluation, as the procedure is likely to be adopted by an increasing number of surgeons. On 12 October 2015, the first educational consensus workshop for TaTME took place. ${ }^{36}$ The need for an agreed training curriculum and how this educational program should be structured was discussed. They proposed the formation of the international TaTME educational collaborative group, to develop a TaTME training curriculum. Following their consensus meeting, they agreed on the steps in the process to achieve a safe implementation: providing shared communication platforms among all stakeholders in the field to drive the educational standard for TaTME, agree on the essential elements of an optimal training curriculum and providing guidance on the implementation and assessment of a training curriculum for TaTME.

Recently, a consensus on this structured training curriculum was proposed by Francis et al. ${ }^{37}$ They recommended that surgeons aiming to learn TaTME should be accredited in laparoscopic colorectal surgery, with prior experience in transanal surgery. The most important aspects of the curriculum were mentorship, multidisciplinary training, online modules and simulated training for purse-string suturing. Entering data into the registry was recommended, as well as a formative assessment to promote learning and competency. 
This structured training program was put into practice into the UK, where a pilot national training program for TaTME was launched in September 2017.

However, due to the promising early results, a rapid introduction of TaTME in many centers without surgeons completing a full training program resulted in an early shift to the Assessment phase.

\section{Stage 3: Assessment}

At this stage, effectiveness of the new technique against current standards is assessed. A new intervention has shown early promise and is used increasingly by the surgical community; however, the intervention's relative benefit compared with conventional approaches is still uncertain. Properly conducted RCTs should be the primary choice, as new techniques are prone to overoptimistic assessment by their developers. ${ }^{8}$ If an RCT is not feasible, which is not exceptional in surgical innovation studies, alternative designs could be used. ${ }^{7}$

The outcomes of the International TaTME Registry also contributed to the set-up of three RCTs. The aim of these studies is to validate the efficacy and safety of TaTME, with respect to perioperative outcomes, short and long-term complications and oncological and functional results. The COLOR III trial ${ }^{38}$ and GRECCAR 11 trial $^{39}$ are international, multicenter, randomized trials comparing TaTME and laparoscopic TME for mid and low rectal carcinomas. The RESET trial ${ }^{40}$ will be a prospective, observational, case-matched, four-cohort, multicenter trial. It is designed to study all surgical options available for TME in patients with rectal cancer: open laparotomy, laparoscopy, robot-assisted surgery, or transanal surgery. Participating surgeons treat all their eligible patients with rectal cancer with their preferred intervention. This design minimizes the influence of the learning curve effect and surgeons might be more willing to participate in expertise-based trials.

Attention will shift to the next phase, once valid evidence on the intervention's relative effectiveness is obtained. At present for TaTME, definitive studies are needed. Furthermore, aspects requiring long-term monitoring should be identified in this stage, in order to set up studies related to the last phase of the IDEAL framework.

\section{Stage 4: Long-term studies}

The evolution of TaTME has not yet reached stage 4, in which procedures are assessed for long-term outcomes. Meticulous surgery with clear view of the dissection plane and of the neurovascular bundles should theoretically provide better bladder, sexual and bowel function. Currently, it remains uncertain if this is true, and what the oncological implications are from this technique. However, the International TaTME Registry and the aforementioned trials gather information on long-term oncological status and quality of life and these outcomes are soon to be expected.
In order to collect these data, it is preferable registries are being set up from the start of implementing a new technique (stage 1). This is often not feasible, as at that stage it is still unknown if the technique will be adopted and if setting up a registry is worthwhile. As for TaTME, the registry was set up fairly soon after the introduction of TaTME. This was beneficial for a quick and early overview of early outcomes from a large patient cohort (as described in stage 2B), and will provide data on learning curve analysis, mid-term and long-term oncological outcomes and long-term quality of life and functional outcomes in the near future.

When large numbers of patients have a sufficient length of follow-up, an investigation of outcome variations among subgroups is recommendable, to prevent unfair comparison of results between different centers or surgeons with varying patient groups.

\section{DISCUSSION}

The quality of clinical research in surgery has long attracted criticism. RCTs, considered the gold standard in evidencebased healthcare, are often difficult to undertake in surgery, and many surgical treatments have therefore been adopted without adequate supporting evidence of efficacy and safety. The timing of introducing a new technique is essential and a balance should be found between waiting for robust evidence before widespread adoption takes place, against depriving patients from a better treatment. Although surgical assessment is often challenging, it is fundamental and achievable. The IDEAL framework specifies desirable qualities for surgical studies and outlines an integrated evaluation pathway for new surgical interventions.

The aim of this article was to describe the evolution of TaTME, guided by the IDEAL principles. For many years, surgery for rectal cancer has evolved from open laparotomy to minimally invasive techniques, while the gold standard to perform a high-quality TME remained the same. TaTME was born from the Idea that visualization of dissection planes for distal tumors was limited using a pure abdominal approach. In the pre-IDEAL phase, extensive preclinical work on animals and cadavers was performed, which showed that a new 'bottom-up' approach was feasible, resulting in the first in human TaTME case in 2010. In the Development phase, the technique was further refined. Next, extensive exploration of safety and outcomes took place in the Exploration phase, owing to the early set-up of the International TaTME Registry. Assessment of the effectiveness of TaTME against current standards can be done after completion of the three (R)CTs. These trials are still ongoing, and follow-up of the registry data is still insufficient to report on Long-term outcomes.

The development of TaTME followed the IDEAL framework quite closely. However, the evolution of TaTME was not initially planned via IDEAL approach, so there are some gaps. The initial promising early results by the early adopters resulted in a TaTME 'hype' with too rapid uptake of the technique by the early majority, without warning for 
the dangers that can be encountered when performing this complex technique. The technique was not completely standardized yet when shifting to the Assessment phase, for instance, the anatomotic technique, and this could explain the relatively high anastomotic leak rate. Future recommendations should include the standardization and obligation of a formal training program for surgeons, before widespread adoption of the technique can take place. Furthermore, besides training to improve the learning curve, a steady case volume is crucial to master any technique. This is why for a complex procedure as TaTME, the technique should early on be introduced only in high-volume centers by surgeons experienced in minimal invasive TME surgery. If not, poor outcomes are to be expected, not because TaTME is a 'bad' technique, but because the procedure is 'badly executed', in poorly selected patients.

Furthermore, guidance statements for safe implementation and training from national societies should have been provided at an earlier stage. International expert guidance statements are about to be published, and provide recommendations regarding indications, quality and outcome measures, training and technique. It will be recommended that registration of all cases on a registry should be mandatory, as well as regular assessments of individual center results.

A limitation of this article is that the overview provided was subject to the personal interpretation of the authors of how TaTME aligned with the IDEAL framework.

Nonetheless, it is important to clarify the lessons learned during adoption and implementation of TaTME, in order to inform other colleagues within the surgical community, who are undoubtedly struggling with the same issues when introducing new surgical techniques. We should learn from each other's experiences to move forward and improve the quality of surgical innovation and research.

Contributors The manuscript was written by SXR and AC. The manuscript was critically revised by all authors. The final version of the manuscript was approved by all authors.

Funding The authors have not declared a specific grant for this research from any funding agency in the public, commercial or not-for-profit sectors.

Competing interests None declared.

Patient consent for publication Not required.

Provenance and peer review Not commissioned; externally peer reviewed.

Open access This is an open access article distributed in accordance with the Creative Commons Attribution Non Commercial (CC BY-NC 4.0) license, which permits others to distribute, remix, adapt, build upon this work non-commercially, and license their derivative works on different terms, provided the original work is properly cited, appropriate credit is given, any changes made indicated, and the use is non-commercial. See: http://creativecommons.org/licenses/by-nc/4.0/.

\section{REFERENCES}

1. US Food and drug administration. Available: https://www.fda.gov/ forpatients/approvals/drugs/ [Accessed 25 Feb 2019].

2. Barkun JS, Aronson JK, Feldman LS, et al. Evaluation and stages of surgical innovations. The Lancet 2009;374:1089-96.

3. Heald RJ, Moran BJ, Ryall RD, et al. Rectal cancer: the Basingstoke experience of total mesorectal excision, 1978-1997. Arch Surg 1998;133:894-9.
4. Heald RJ, Ryall RDH. Recurrence and survival after total mesorectal excision for rectal cancer. The Lancet 1986;327:1479-82.

5. Marks JH, Frenkel JL, D'Andrea AP, et al. Maximizing rectal cancer results: TEM and TATA techniques to expand sphincter preservation. Surg Oncol Clin N Am 2011;20:501-20.

6. Atallah S, Albert M, Larach S. Transanal minimally invasive surgery: a giant leap forward. Surg Endosc 2010;24:2200-5.

7. Ergina PL, Cook JA, Blazeby JM, et al. Challenges in evaluating surgical innovation. The Lancet 2009;374:1097-104.

8. McCulloch P, Altman DG, Campbell WB, et al. No surgical innovation without evaluation: the ideal recommendations. The Lancet 2009;374:1105-12.

9. Hirst A, Philippou Y, Blazeby J, et al. No surgical innovation without evaluation: evolution and further development of the ideal framework and recommendations. Ann Surg 2018.

10. Whiteford MH, Denk PM, Swanström LL. Feasibility of radical sigmoid colectomy performed as natural orifice translumenal endoscopic surgery (Notes) using transanal endoscopic microsurgery. Surg Endosc 2007;21:1870-4.

11. Sylla P, Willingham FF, Sohn DK, et al. Notes rectosigmoid resection using transanal endoscopic microsurgery (TEM) with transgastric endoscopic assistance: a pilot study in swine. J Gastrointest Surg 2008;12:1717-23.

12. Leroy J, Cahill RA, Perretta S, et al. Natural orifice translumenal endoscopic surgery (Notes) applied totally to sigmoidectomy: an original technique with survival in a porcine model. Surg Endosc 2009;23:24-30.

13. Sylla P, Sohn DK, Cizginer S, et al. Survival study of natural orifice translumenal endoscopic surgery for rectosigmoid resection using transanal endoscopic microsurgery with or without transgastric endoscopic assistance in a swine model. Surg Endosc 2010;24:2022-30.

14. Telem DA, Han KS, Kim M-C, et al. Transanal rectosigmoid resection via natural orifice translumenal endoscopic surgery (Notes) with total mesorectal excision in a large human cadaver series. Surg Endosc 2013;27:74-80.

15. Sylla P, Rattner DW, Delgado S, et al. Notes transanal rectal cancer resection using transanal endoscopic microsurgery and laparoscopic assistance. Surg Endosc 2010;24:1205-10.

16. Lacy AM, Adelsdorfer C, Delgado S, et al. Minilaparoscopy-assisted transrectal low anterior resection (LAR): a preliminary study. Surg Endosc 2013;27:339-46.

17. de Lacy AM, Rattner DW, Adelsdorfer C, et al. Transanal natural orifice transluminal endoscopic surgery (NOTES) rectal resection: "down-to-up" total mesorectal excision (TME) - short-term outcomes in the first 20 cases. Surg Endosc 2013;27:3165-72.

18. Muratore A, Mellano A, Marsanic P, et al. Transanal total mesorectal excision (taTME) for cancer located in the lower rectum: shortand mid-term results. European Journal of Surgical Oncology 2015;41:478-83.

19. Tuech JJ, Karoui M, Lelong B, et al. A step toward notes total mesorectal excision for rectal cancer: endoscopic transanal proctectomy. Ann Surg 2015;261:228-33.

20. Transanal Total Mesorectal Excision International Registry [TaTME website]. Available: https://tatme.medicaldata.eu/ [Accessed $18 \mathrm{Jul}$ 2018].

21. Motson RW, Whiteford MH, Hompes R, et al. Current status of trans-anal total mesorectal excision (TaTME) following the second international consensus Conference. Colorectal Dis 2016;18:13-18.

22. Bernstein M, Bampoe J. Surgical innovation or surgical evolution: an ethical and practical guide to handling novel neurosurgical procedures. J Neurosurg 2004;100:2-7.

23. Nicholson G, Knol J, Houben B, et al. Optimal dissection for transanal total mesorectal excision using modified $\mathrm{CO}$ insufflation and smoke extraction. Colorectal Dis 2015;17:0265-0267.

24. Bernardi M-P, Bloemendaal ALA, Albert M, et al. Transanal total mesorectal excision: dissection tips using 'O's and 'triangles'. Tech Coloproctol 2016;20:775-8.

25. Atallah S, Mabardy A, Volpato AP, et al. Surgery beyond the visible light spectrum: theoretical and applied methods for localization of the male urethra during transanal total mesorectal excision. Tech Coloproctol 2017;21:413-24.

26. Ito M, Sugito M, Kobayashi A, et al. Relationship between multiple numbers of stapler firings during rectal division and anastomotic leakage after laparoscopic rectal resection. Int J Colorectal Dis 2008;23:703-7.

27. Penna M, Knol JJ, Tuynman JB, et al. Four anastomotic techniques following transanal total mesorectal excision (TaTME). Tech Coloproctol 2016;20:185-91.

28. Arroyave MC, DeLacy FB, Lacy AM. Transanal total mesorectal excision (TaTME) for rectal cancer: step by step description of the 
surgical technique for a two-teams approach. European Journal of Surgical Oncology 2017;43:502-5.

29. Burke JP, Martin-Perez B, Khan A, et al. Transanal total mesorectal excision for rectal cancer: early outcomes in 50 consecutive patients. Colorectal Dis 2016;18:570-7.

30. Veltcamp Helbach M, Deijen CL, Velthuis S, et al. Transanal total mesorectal excision for rectal carcinoma: Short-term outcomes and experience after 80 cases. Surg Endosc 2016;30:464-70.

31. Lacy AM, Tasende MM, Delgado S, et al. Transanal total mesorectal excision for rectal cancer: outcomes after 140 patients. Journal of the American College of Surgeons 2015;221:415-23.

32. Penna M, Hompes R, Arnold S, et al. Transanal total mesorectal excision: international registry results of the first 720 cases. Ann Surg 2017;266:111-7.

33. Atallah SB, DuBose AC, Burke JP, et al. Uptake of transanal total mesorectal excision in North America: initial assessment of a structured training program and the experience of Delegate surgeons. Dis Colon Rectum 2017;60:1023-31.

34. Penna M, Hompes R, Arnold S, et al. Incidence and risk factors for anastomotic failure in 1594 patients treated by transanal tota mesorectal excision: results from the International TaTME registry. Ann Surg 2018.
35. Dickson EA, Penna M, Cunningham C, et al. Carbon dioxide embolism associated with total mesorectal excision surgery: a report from the International registries. Disease of the Colon\&Rectum. In Press 2019; XX

36. Penna $\mathrm{M}$, Hompes $\mathrm{R}$, Mackenzie $\mathrm{H}$, et al. First international training and assessment consensus workshop on transanal total mesorectal excision (taTME). Tech Coloproctol 2016;20:343-52.

37. Francis N, Penna M, Mackenzie $\mathrm{H}$, et al. Consensus on structured training curriculum for transanal total mesorectal excision (TaTME). Surg Endosc 2017;31:2711-9.

38. Deijen CL, Velthuis S, Tsai A, et al. Color III: a multicentre randomised clinical trial comparing transanal Tme versus laparoscopic Tme for mid and low rectal cancer. Surg Endosc 2016;30:3210-5.

39. Lelong $\mathrm{B}$, de Chaisemartin $\mathrm{C}$, Meillat $\mathrm{H}$, et al. A multicentre randomised controlled trial to evaluate the efficacy, morbidity and functional outcome of endoscopic transanal proctectomy versus laparoscopic proctectomy for low-lying rectal cancer (ETAPGRECCAR 11 trial): rationale and design. BMC Cancer 2017;17.

40. Rouanet P, Gourgou S, Gogenur I, et al. Rectal surgery evaluation trial: protocol for a parallel cohort trial of outcomes using surgical techniques for total mesorectal excision with low anterior resection in high-risk rectal cancer patients. Colorectal Dis 2019;21:516-22. 
Correction: Evolution of transanal total mesorectal excision according to the IDEAL framework

Roodbeen SX, lo Conte A, Hirst A, et al. Evolution of transanal total mesorectal excision according to the IDEAL framework. BMJ Surg Interv Health Technologies 2019;1:e000004. doi: 10.1136/bmjsit-2019-000004

This article has been corrected since it published Online First.

Open access This is an open access article distributed in accordance with the Creative Commons Attribution Non Commercial (CC BY-NC 4.0) license, which permits others to distribute, remix, adapt, build upon this work non-commercially, and license their derivative works on different terms, provided the original work is properly cited, appropriate credit is given, any changes made indicated, and the use is non-commercial. See: http://creativecommons.org/licenses/by-nc/4.0/

C Author(s) (or their employer(s)) 2019. Re-use permitted under CC BY-NC. No commercial re-use. See rights and permissions. Published by BMJ.

BMJ Surg Interv Health Technologies 2019;1:e000004corr1. doi:10.1136/bmjsit-2019-000004corr1

A Check for updates 